\title{
СИБИРСКАЯ ЯЗВА: ЖИЗНЕННЫЙ ЦИКЛ, МЕХАНИЗМЫ ПАТОГЕНЕЗА И НОВЫЕ КОНЦЕПЦИИ В РАЗВИТИИ ВЕТЕРИНАРНЫХ ВАКЦИН*
}

\author{
(обзор)
}

\author{
О.А. КОНДАКОВА ${ }^{凶}$, Н.А. НИКИТИН, Е.А. ЕВТУШЕНКО, Д.Л. ГРАНОВСКИЙ, \\ И.Г. АТАБЕКОВ, О.В. КАРПОВА
}

Сибирская язва - особо опасное заболевание сельскохозяйственных и диких животных, а также человека, вызываемое грамположительной спорообразующей бактерией Bacillus anthracis. Инфекция имеет глобальное распространение, но уровень заболеваемости сельскохозяйственных животных и людей варьируется в зависимости от экологической ситуации и реализации стратегий контроля (C.J. Carlson с соавт., 2019). Исторический и современный опыт свидетельствует о том, что бесконтрольные вспышки сибирской язвы могут иметь катастрофические последствия. В данном обзоре рассматриваются жизненный цикл возбудителя, экологические особенности распространения сибирской язвы, механизмы патогенеза и описывается, как с учетом понимания данных факторов на протяжении многих лет развиваются оптимальные с точки зрения затрат и результата стратегии борьбы с этой опасной инфекцией. Своевременная утилизация погибших особей и вакцинирование здорового поголовья скота, применяемые в совокупности, могут эффективно останавливать распространение заболевания. Это делает задачу разработки высокоэффективных, безопасных и дешевых вакцин крайне актуальным и, более того, фактически единственным перспективным методом улучшения эпизоотической ситуации с этим опасным заболеванием. Вакцинация сельскохозяйственных животных в течение нескольких десятилетий значительно сократила риск возникновения сибирской язвы, но она не является обязательной во многих странах и часто используется только после возникновения заболевания, а не для его предотвращения. Несмотря на значительное снижение заболеваемости, современная ситуация с сибирской язвой в Российской Федерации может быть определена как неустойчивая (А.Г. Рязанова с соавт., 2018; Е.Г. Симонова с соавт., 2018). В стране по-прежнему регистрируются эпизоотии среди животных и случаи заболевания у людей. Это обусловлено наличием естественных почвенных резервуаров возбудителя и неполным охватом вакцинацией против сибирской язвы сельскохозяйственных животных. В настоящее время для вакцинации сельскохозяйственных животных используются только живые аттенуированные вакцины. В обзоре суммированы сведения об их эффективности и безопасности, а также ограничениях, связанных с применением живых аттенуированных вакцин. Несмотря на то, что существующие вакцины показали свою эффективность, они имеют ряд недостатков. Актуальность разработки более эффективных ветеринарных вакцин против сибирской язвы, основанных на современных подходах, полностью обоснована. В частности, существует необходимость в создании ветеринарной вакцины, не содержащей возбудителя в любых формах и совместимой с приемом антибиотиков, которые необходимы как во время вспышки сибирской язвы, так и для регулярного использования при лечении различных заболеваний животных. Создание современных рекомбинантных вакцин и отказ от использования патогенов в аттенуированной форме является важной и перспективной задачей. В обзоре дан анализ исследований по созданию новых кандидатных вакцин против сибирской язвы. Основное внимание уделено разработкам субъединичных вакцин с использованием рекомбинантных антигенов $B$. anthracis, полученных в различных системах экспрессии, в том числе для перорального введения и совместимых с приемом антибиотиков.

Ключевые слова: сибирская язва, Bacillus anthracis, ветеринарные вакцины, рекомбинантные антигены

Сибирская язва представляет собой зоонозную особо опасную инфекционную болезнь, возбудитель которой - грамположительная спорообразующая бактерия Bacillus anthracis - относится ко II группе патогенности. К сибирской язве восприимчивы почти все виды теплокровных животных, включая человека (1). Для травоядных животных источником заражения служит почва, содержащая споры B. anthracis. Высокая устойчивость спор сибирской язвы к воздействию факторов внешней среды, способность

\footnotetext{
* Работа выполнена при поддержке Российского научного фонда в рамках приоритетного направления деятельности РНФ «Проведение фундаментальных научных исследований и поисковых научных исследований отдельными научными группами» (грант № 18-14-00044).
} 
длительно сохраняться в почве, а также при определенных условиях переходить в вегетативную форму делает борьбу с этой инфекцией чрезвычайно сложной задачей медицины и ветеринарии. Человек заражается контактнобытовым путем от контаминированных объектов животного происхождения, и в мире ежегодно заболевают от 2000 до 20000 человек (2). Подсчитано, что 1,83 млрд человек живут в районах, подверженных риску возникновения вспышки сибирской язвы (3). В некоторых регионах вспышки заболевания являются последовательной и предсказуемой особенностью экосистем и происходят регулярно на определенном этапе сезонного цикла, в других местах эпизоотии редки и могут быть причиной массовой гибели среди диких животных и домашнего скота (4-7). Климатические условия считаются общепризнанным фактором активизации природных очагов и риска возникновения эпизоотий сибирской язвы среди травоядных животных, особенно в эндемичных регионах (8-12). Несмотря на то, что сибирскую язву изучают около 130 лет, остается много нерешенных вопросов, связанных с патогенезом и эпидемиологией заболевания (13).

Используемая в большинстве стран мира современная ветеринарная вакцина против сибирской язвы, разработанная в 1937 году (14), представляет собой бескапсульный, но токсигенный штамм Sterne 34F2 или его аналоги (Россия, Китай, Румыния). Несмотря на то, что существующие вакцины показали свою эффективность, они имеют ряд недостатков. В частности, парентеральный способ введения вакцины непрактичен при массовой иммунизации животных, особенно животных, находящихся на свободном выпасе. Однако пероральное введение вакцины Sterne 34F2 оказалось неэффективным (15). Разработку новых концепций и отказ от патогенов в аттенуированной форме как основы вакцинных препаратов относят к числу важных и перспективных задач исследований.

В представленном обзоре обсуждается актуальность рекомбинантных сибиреязвенных вакцин нового поколения и используемые для их разработки современные методы и подходы. Также рассмотрены эффективность и безопасность применения живых аттенуированных вакцин.

Жизненный цикл возбудителя, экологические и эпизоотические особенности сибирской язвы. Сибирская язва относится к природно-очаговым сапронозным инфекциям $(16,17)$. Болезнь поражает главным образом травоядных животных. Крупный рогатый скот, лошади, олени, овцы и козы наиболее восприимчивы к B. anthracis. В некоторых случаях эпизоотии сибирской язвы в дикой природе могут привести к заражению сельскохозяйственных животных и людей. B. anthracis встречается в двух формах - в виде вегетативных клеток и в виде спор, что обусловливает важнейшие эпизоотические особенности сибирской язвы. Общепринято, что основной путь заражения - алиментарный, при котором споры попадают в организм животного с кормом или водой, однако возможно заражение через кожу и дыхательные пути. При этом часто возникают аномалии в эпизоотиях сибирской язвы, которые трудно объяснить прямым проникновением спор в организм во время выпаса скота. По-видимому, насекомые способны играть роль переносчиков спор при непрогнозируемых вспышках заболевания (18-20). Человеческая деятельность и экологические факторы также могут иметь важное значение в возникновении эпизоотий сибирской язвы $(12,21-23)$. После заражения и смерти животных вегетативные клетки B. anthracis попадают в окружающую среду (с кровью и другими биологическими жидкостями) и при контакте с кислородом превращаются в споры. Обсеменение почвы спорами после гибели больных животных составляет 
обязательное условие непрерывности циркуляции возбудителя сибирской язвы. При участии животных-падальщиков, насекомых (биотические процессы) или вследствие действия абиотических факторов (вода или ветер) споры сибирской язвы из первичных почвенных очагов могут переноситься на другие территории, в том числе в районы, ранее свободные от инфекции $(19,20,22,24)$. Споры чрезвычайно устойчивы к факторам внешней среды и могут сохраняться в почве десятилетиями (23). Вспышка сибирской язвы у оленей в Ямало-Ненецком округе в 2016 году (спустя 75 лет после последнего известного в регионе случая) свидетельствует о том, что потенциальное время персистенции $B$. anthracis в окружающей среде может превышать столетия (11). Однако количество спор B. anthracis в пробах почвы и воды в районах могильников животных, павших от сибирской язвы, быстро снижается до уровня ниже порога обнаружения, что объясняют эффективным рассеиванием спор животными, дождевой водой и ветром, а также относительно низкой жизнеспособностью вегетативных клеток и спор $B$. anthracis в окружающей среде (8). Было выдвинуто предположение, что до заражения животных $B$. anthracis размножается в почве в местах, называемых инкубационными зонами. Почвы, богатые кальцием и органическими веществами, при $\mathrm{pH}>6,0$ и температуре выше $15^{\circ} \mathrm{C}$ благоприятствуют размножению бактерий в топографически четко определенных областях, в которых происходит заражение животных и возникают вспышки сибирской язвы $(8,10)$. В смоделированных условиях окружающей среды показано, что споры вирулентного штамма Ames и вакцинного штамма Sterne прорастали и размножались внутриклеточно в свободноживущей почвенной амебе (Acanthamoeba castellanii), и через 72 ч после инокуляции наблюдалось 50-кратное увеличение числа спор (25). В другой работе продемонстрировано, что инокуляция спорами ризосферы также может приводить к их прорастанию (26). Оказалось, что важную роль в жизненном цикле сибирской язвы играют также бактериофаги. Лизогения может стимулировать или, наоборот, блокировать споруляцию (в зависимости от бактериофага), вызывая фенотипические изменения $B$. anthracis и обеспечивая долговременную бактериальную колонизацию как в искусственной почвенной среды, так и в кишечнике навозного червя (Eisenia fetida) (27). Показано, что вегетативные клетки могут сохраняться в почве до 120 ч, а введенная в верхний слой почвы смесь спор и вегетативных клеток сохраняется в нем 56 сут (28). Постоянный цикл хозяин-почва-хозяин составляет основу для возникновения повторных вспышек. Люди заражаются сибирской язвой контактно-бытовым путем от инфицированных животных, также описано несколько случаев передачи заболевания через укусы насекомых (1). Возможность передачи сибирской язвы от больного человека к здоровому не зафиксирована. Любая вспышка сибирской язвы может иметь катастрофические последствия, если ее не контролировать. Обычно у большинства животных сибирская язва развивается очень быстро, и не всегда удается осуществить успешное лечение. Заболевание имеет глобальное распространение, но заболеваемость сельскохозяйственных животных и людей варьируется в зависимости от местной экологии и реализуемых стратегий контроля (3). Вакцинация сельскохозяйственных животных в экономически развитых странах в течение многих десятилетий значительно сократила риск возникновения сибирской язвы. Основной причиной эпизоотии сибирской язвы в Ямало-Ненецком округе в 2016 году, когда пало свыше 2600 северных оленей и заболели 36 человек с одним летальным исходом, был отказ от вакцинации северных оленей на протяжении предшествующих 9 лет (11). Большинство развитых стран 
сообщают о спорадических случаях заболевания у скота и людей, но эта болезнь все еще остается энзоотической в некоторых районах Африки, на Ближнем Востоке и в Центральной Азии. Несмотря на значительное снижение заболеваемости, современная ситуация по сибирской язве в Российской Федерации также характеризуется как неустойчивая (29-31). В стране по-прежнему регистрируются эпизоотии среди животных и случаи заболевания у людей. Это обусловлено наличием естественных почвенных резервуаров возбудителя и неполным охватом вакцинацией против сибирской язвы сельскохозяйственных животных. На территории Российской Федерации насчитывается свыше 35 тыс. стационарно неблагополучных по сибирской язве пунктов (СНП). При этом существует высокая вероятность наличия значительного количества неучтенных захоронений (32). Большинство зарегистрированных в последние годы вспышек болезни возникло в известных, учтенных СНП, причем в некоторых из них активность почвенных очагов сибирской язвы не проявлялась в течение последних 40-60 лет. В то же время некоторые эпизоотические очаги возникли на территориях, считавшихся благополучными (33). Также есть сообщения о вспышках сибирской язвы в дикой природе в различных экосистемах по всему миру $(5,7,34)$.

Ошибочно считать сибирскую язву наследием какого-то санитарного неблагополучия прошлого, плохо утилизированных скотомогильников и пр. По всей видимости, в природе существуют множественные естественные резервуары спор возбудителя, у которого в цикле развития имеются фазы покоя и интенсивного развития. Активация спор может происходить в результате природных и климатических явлений: наводнений или засух, резкого изменения температурного режима, оттаивания почвы, оползней и др. В частности, это подтверждает периодическая массовая гибель диких животных от сибирской язвы на охраняемых природных территориях Африки. Так, сотни бегемотов погибли от сибирской язвы в 2017 году в Национальном парке Бвабвата (Bvabvata National Park) на северо-востоке Намибии в период необычно низкого уровня воды в реках (7). Вспышку сибирской язвы на Ямале также связывают с аномально жаркой погодой, что способствовало увеличению глубины сезонного таяния многолетней мерзлоты до 1 м и перемещению спор из глубинных слоев к поверхности почвы. Такие почвенные условия благоприятны для спорообразования и вегетации возбудителя. Наблюдаемые климатические факторы дополнительно способствовали увеличению численности кровососущих насекомых, которые рассматриваются в качестве переносчика возбудителя и причины быстрого распространения эпизоотий $(11,16,35)$. Активность возникающих очагов проявляется только в заболевании и гибели животных. При этом сам природный очаг возбудителя часто не удается выявить и локализовать. Принятая практика борьбы с инфекцией крупного рогатого скота включает утилизацию трупов и вакцинирование животных, находящихся на пастбищном содержании.

Поиск оптимальной стратегии борьбы с распространением заболевания (с точки зрения затрат и эффекта) недавно был осуществлен с помощью современных методов математического моделирования (36). Результаты расчетов американских исследователей свидетельствуют о том, что только сочетание своевременной утилизации погибших особей с вакцинированием здорового поголовья останавливает распространение сибирской язвы. Это делает разработку современных, дешевых и эффективных сибиреязвенных вакцин очень актуальным и, более того, фактически един- 
ственным перспективным способом улучшения эпизоотической ситуации в отношении такого опасного заболевания, как сибирская язва.

Механизмы патогенеза. После попадания спор B. anthracis в opганизм восприимчивого хозяина (по желудочно-кишечному, ингаляционному пути или через кожу) они могут прорасти в вегетативную форму локально на первичных участках контакта. Также споры могут захватываться макрофагами и переноситься в лимфатические узлы, где прорастают в вегетативную форму, мигрируют в кровоток и выделяют токсины, которые вызывают системные эффекты. Основными факторами вирулентности вегетативной формы $B$. anthracis служат капсула, состоящая из поли-y-D-глутаминовой кислоты, и токсины сибирской язвы. Капсула обладает низкой иммуногенностью и придает устойчивость бактерий к фагоцитозу и системе комплемента. Образование компонентов капсулы кодирует плазмида рXО2. В результате возбудитель становится неуязвимым для иммунной системы хозяина $(37,38)$. Токсины сибирской язвы представляют собой три белка, кодируемые плазмидой рXО1, - протективный антиген (РА), летальный фактор (LF) и отечный фактор (EF), которые объединяются в бинарные комплексы PA/LF и PA/EF с образованием соответственно летального токсина (LT) и отечного токсина (ЕT) (39).

РА представляет собой белок с молекулярной массой 83 кДа (РА83). После связывания РА83 с клеточными рецепторами (белком капиллярного морфогенеза 2 - CMG2 и эндотелиальным маркером опухоли 8 - TEM8) происходит протеолитический гидролиз белка клеточными поверхностными фуриноподобными протеазами с отщеплением от не участвующего во взаимодействии с рецепторами N-конца фрагмента PA массой 20 кДа (РА20), в результате чего с рецептором остается связан только С-концевой фрагмент РА массой 63 кДа (РА63). Рецептор СMG2 имеет более высокое сродство к РА83, широко экспрессируется в различных типах клеток и считается основным рецептором токсина сибирской язвы, опосредующим летальность in vivo, тогда как TEM8 играет второстепенную роль в патогенезе сибирской язвы (40). Оба рецептора имеют высокую степень идентичности между собой и содержат консервативный домен, с которым связывается РА (41, 42). CMG2 высококонсервативен среди различных видов животных, которые его экспрессируют (например, степень идентичности CMG2 человека и мыши составляет 82 \%), но обнаруживается только у позвоночных. Можно предположить, что консервативность клеточных рецепторов и РА служит одной из причин отсутствия резистентности к этому патогену у широкого спектра видов млекопитающих. Показано, что, подобно фурину, РА83 является кальций-зависимой сериновой протеазой и что белок потенциально может использовать эту протеолитическую активность для связывания с рецептором ТЕМ8 (43). РА63 в комплексе с рецептором образует олигомеры (гептамеры или октамеры), с которыми связываются три или четыре LF, EF либо LF и EF одновременно. Токсинный комплекс подвергается эндоцитозу. Под действием кислого рН эндосомы происходит ряд конформационных изменений в структуре олигомера РА63, и в конечном итоге в эндосомальной мембране образуется канал, через который LF и EF переносятся в цитозоль клетки, где проявляют свою токсичность, обусловленную их ферментативной активностью (44-46). Недавно описана новая функция РА20 и предложен РА20-опосредованный механизм, с помощью которого насекомые - переносчики B. anthracis, приобретают устойчивость к сибирской язве за счет активации врожденного иммунитета. По мнению авторов, подобный механизм может существовать и у млекопитающих (47).

LF - это цинк-зависимая металлопротеаза, которая расщепляет 
митоген-активируемые протеинкиназы MAPKKs, MEKs и MKKs, нарушая активацию сигнальных путей митоген-активируемых протеинкиназных каскадов, включая пути ERK (Киназа, регулируемая внеклеточным сигналом, Exracellular signal-regulated kinase) 1/2, JNK/SAPK (Киназа N-концевой части фактора транскрипции Jun/Стресс-активируемая протеин-киназа - c-Jun $\mathrm{N}$-terminal kinase/Stress activated protein kinase) и р38, которые важны для многочисленных клеточных функций, таких как пролиферация и регуляция клеточного цикла, а также для иммуномодуляции и выживания при токсических инсультах (48-50). ЕF представляет собой высокоэффективную кальмодулин-зависимую аденилатциклазу, которая примерно в 1000 раз более активна, чем аденилатциклаза млекопитающих, и вызывает устойчивое повышение уровня цАМФ. Высокие концентрации цАМФ нарушают ключевые клеточные функции, что приводит к серьезным последствиям для хозяина (51-54).

В настоящее время не подлежит сомнению, что токсины сибирской язвы имеют решающее значение в ее патогенезе. Выделение токсинов происходит на ранних стадиях после прорастания спор: мРНК РА обнаруживается через 15 мин после инициации прорастания (55). Однако механизмы патогенеза неодинаковы у разных видов животных, зависят от формы заболевания и других факторов. На начальных стадиях инфекции совместное действие LT и ET блокирует врожденный иммунный ответ хозяина. Например, известен феномен LT-индуцированной гибели макрофагов у некоторых линий мышей. На поздних стадиях, когда достигаются высокие концентрации LT и ET, они могут напрямую вызывать смерть хозяина посредством воздействия на различные жизненно важные системы, в частности на сердечно-сосудистую систему и печень $(40,56)$. В экспериментах на мышах показано, что экспрессия основного рецептора токсина CMG2 в гладкомышечных клетках сосудов и кардиомиоцитах необходима для летального исхода, индуцированного LT. Смертность, вызванная ET, происходит из-за повреждения другого типа клеток, главным образом гепатоцитов. Нацеливание на эндотелиальные клетки любым из токсинов не вносит значительного вклада в смертность от $B$. anthracis, как это предполагалось ранее (56). Таким образом, как LT, так и ET летальны для мышей, тогда как три компонента токсина (PA, LF и EF) по отдельности не являются токсичными (57). В то же время в экспериментах на макаках показано, что патологические эффекты, приводящие к летальному исходу, обусловлены главным образом действием летального токсина сибирской язвы (58). Исследование влияния LT и ET на подгруппы альвеолярных фагоцитов и лейкоцитов человека с невысокой экспрессией CMG2 и TЕM8 продемонстрировало, что все типы клеток связывали РА дозозависимым образом. Клетки были нечувствительны к LT-индуцированному апоптозу или некрозу при концентрациях токсина ниже 1000 нг/мл. Однако воздействие токсинов ингибировало интернализацию спор. Авторы предполагают, что при легочной форме сибирской язвы ЕТ предотвращает фагоцитоз спор на ранних стадиях, а на поздних стадиях заболевания высокая концентрация LT в кровотоке подавляет фагоцитоз патогена лейкоцитами, обеспечивая таким образом быстрое размножение $B$. anthraxis в крови (59). Возможно, такой же механизм существует и у некоторых других видов животных. Длительное хранение активных ферментов (LF) в эндосомальных везикулах и их медленное выделение во внешнюю среду, которое возможно даже в отсутствие бактерий, служит важной характеристикой высокой вирулентности $B$. anthracis. По-видимому, это является причиной летальных исходов даже после успешного уничто- 
жения бактерий при лечении антибиотиками (60).

Живые аттенуированные вакцины. Сибирская язва была одним из первых бактериальных заболеваний, которые стали контролировать с помощью вакцинации. Первые живые ослабленные (аттенуированные) вакцины против сибирской язвы были разработаны Луи Пастером в 1881 году и эффективно использовались для вакцинации животных в Европе и Южной Америке в течение 50 лет. Живые аттенуированные вакцины для ветеринарного применения можно разделить на три основные категории: вакцины Pasteur, вакцины Sterne и вакцины Carbozoo. Деление основано на различных механизмах ослабления патогена (61). Предполагалось, что аттенуация по схеме Пастера (вакцины Pasteur) ведет к элиминации плазмиды pXO1, кодирующей основные факторы вирулентности (PA, LF, EF), что приводит к образованию нетоксигенного и капсулированного (pXO1-/pXO2+) вакцинного штамма. В настоящее время считается, что вакцины Пастера были смешанными культурами, содержащими небольшой процент полностью вирулентных бактерий (рXО1+/pXО2+) (62-64). Механизм аттенуации вакцин типа Carbozoo до сих пор неизвестен, но исследования продемонстрировали присутствие у таких штаммов обеих плазмид (pXO1+/pXO2+) с хромосомными мутациями. Эти вакцинные штаммы относятся к токсигенным и капсулированным (65).

В 1930-е годы вакцины типа Pasteur были вытеснены вакцинами на основе аттенуированных бескапсульных штаммов B. anthracis (pXO1+/pXO2-, вакцины типа Sterne). В вакцинах типа Sterne у B. anthracis отсутствует плазмида рXО2, кодирующая образование компонентов капсулы (pXO1+/pXO2-). Во всем мире в большинстве вакцин против сибирской язвы для животных используется токсигенный некапсулированный штамм $B$. anthracis Sterne 34F2, полученный из вирулентного изолята, выделенного от крупного рогатого скота. В России, Китае и Румынии используются другие аналогичные токсигенные и некапсулированные штаммы (1). В СССР живые вакцины на основе бескапсульных штаммов СТИ-1 и ГНКИ применялись для вакцинации в 1940-1980-е годы, в результате чего было зафиксировано значительное сокращение случаев заболевания сибирской язвой как у людей, так и у животных. С 1980-х годов и по настоящее время в России в качестве вакцинного штамма для домашнего скота используется аттенуированный штамм B. anthracis 55-VNIIVViM (pXO1+/pXO2-). В Италии и Аргентине для вакцинации животных применяют вакцины типа Carbozoo на основе итальянского вакцинного штамма Carbosap (66) и аргентинского штамма А (67).

Sterne-подобные штаммы (34F2 и его аналоги в России, Румынии и Китае) не имеют генов для образования капсул, но все еще продуцируют токсин. Указанные штаммы скорее обладают пониженной вирулентностью, чем относятся к авирулентным, поэтому некоторый уровень заболеваемости при их использовании сохраняется (1). Передозировка вакцинами на основе этих штаммов опасна и может привести к очень серьезным последствиям вплоть до гибели животных. Некоторые животные, например козы, более других подвержены заражению и гибели в подобных случаях, что требует особенно тщательного контроля дозировок $(1,14)$. Также сообщалось, что вакцинация штаммом Sterne 34F2 может приводить к гибели миниатюрных лошадей (68) и лам (69). Для российского штамма 55-VNIIVViM вакцинация лошадей рекомендована только с 9-месячного возраста. Не рекомендуется прививать стельных, больных или слабых животных, также запрещена вакцинация менее чем за 6 нед до убоя животных на мясо. Другие 
факторы, ограничивающие применение существующих в настоящее время вакцин, это высокая стоимость препарата, ограниченный по времени эффект (в эпидемически неблагоприятных регионах прививку нужно повторять ежегодно), необходимость парентерального введения вакцины (уменышение протективного действия и появление побочных эффектов возможны даже при незначительных отступлениях от рекомендаций по дозировкам и регламенту вакцинации), кроме того, наличие живых спор возбудителя сибирской язвы в вакцине требует специальной подготовки персонала, а все использованные флаконы и другая посуда должны быть подвергнуты последующей стерилизации или дезинфекции (1). В 2020 году поступило сообщение о разработке вакцины на основе спор микрокапсулированного атеннуированного штамма B. anthracis Sterne 34F2 для перорального введения. Эксперименты на мышах продемонстрировали иммуногенность и нейтрализующую активность против летальной дозы LT in vitro после одной иммунизации с помощью желудочного зонда (70). Это направление может оказаться перспективным. Однако необходимо дальнейшее изучение протективности микрокапсулированных спор в отношении сельскохозяйственных животных и безопасности таких штаммов для окружающей среды в случае использования для диких животных и животных, находящихся на свободном выгуле.

Кроме того, живые аттенуированные вакцины недостаточно эффективны во время вспышек сибирской язвы, так как только у 80 \% вакцинированных животных развивается достаточный иммунитет, чтобы противостоять инфекции $B$. anthracis через 8 сут после первой вакцинации (71). Поскольку иммунитет возникает более чем через 1 нед после вакцинации, животным рекомендуется сначала длительный курс приема антибиотиков, а только затем вакцинация. Введение вакцины несовместимо с приемом антибиотиков: 2 нед до и после вакцинации животным не следует назначать антибиотики из-за их ингибирующего воздействия на формирование иммунного ответа и возможных анафилактических реакций $(1,72)$. Антибиотики широко применяются для лечения различных заболеваний сельскохозяйственных животных и могут содержаться в корме, что также ограничивает возможности эффективной вакцинопрофилактики сибирской язвы с помощью живых аттенуированных вакцин (1).

Таким образом, разработка альтернативной безопасной для применения и совместимой с антибиотиками вакцины, производство которой будет экономически эффективным, крайне важна.

Р екомб инантны е в а кцины. Создание рекомбинантных вакцин представляет собой многообещающую стратегию, с помощью которой можно преодолеть ограничения, возникающие при использовании традиционных вакцин. Многие успешно созданные рекомбинантные субъединичные и векторные ветеринарные вакцины против различных патогенов животных уже успешно используются для вакцинации (73).

В последние годы активно разрабатываются рекомбинантные вакцины против сибирской язвы как медицинского, так и ветеринарного назначения. Потенциальная возможность использования спор B. anthracis в качестве биологического оружия послужило толчком к интенсивным исследованиям с целью создания сибиреязвенных вакцин нового поколения для людей. В обзоре, опубликованном нами в журнале «Expert Review of Vaccines» в 2019 году, отмечено, что за прошедшие годы были предприняты значительные усилия по разработке новых подходов к вакцинации против сибирской язвы и изучению конструируемых рекомбинантных вакцин (74). 
Основное направление современных исследований в этой области сфокусировано на создании рекомбинантных сибиреязвенных вакцин, включающих последовательность протективного антигена (РА) - основного антигена токсина сибирской язвы. РА является центральным компонентом токсинов и играет ключевую роль в защите против токсигенных и капсулированных штаммов $B$. anthracis. Индукция антител против PA - основной иммунный ответ после вакцинации животных вакциной типа Sterne (75-77). Во многих исследованиях также показано, что протективная эффективность вакцин коррелирует с титрами нейтрализующих антител, индуцируемых РА. Большинство эпитопов, антитела к которым обладают токсин-нейтрализующей активностью, картированы на РА (74).

Кандидатные вакцины против сибирской язвы разрабатываются с использованием различных подходов, которые можно разделить на четыре группы: вакцины на основе аденовирусных векторов, экспрессирующие полноразмерный рекомбинантный PA (rPA83) $(78,79)$; вакцины на основе живых бактериальных векторов, таких как Lactobacillus spp., и аттенуированных штаммов Salmonella spp., экспрессирующие rPA83 (80-84); ДНКвакцины (85-87); вакцины на основе рекомбинантных антигенов B. anthracis, полученных в системах экспрессии in vitro. Большинство разрабатываемых в настоящее время вакцин основано на последнем подходе. Из 10 вакцин, находящихся в клинических исследованиях, восемь получены на основе очищенного rPA83. Субъединичные вакцины на основе очищенного rPA83 имеют хороший профиль безопасности и протективности (74). Кандидатные субъединичные вакцины, в свою очередь, можно разделить на три группы: вакцины на основе rPA83, полученного в различных системах экспрессии (88-92); вакцины на основе химерных белков, полученных слиянием или конъюгацией rPA83 или отдельных доменов РА с дополнительными антигенами для усиления иммунного ответа, такими как домены LF (93-97), LF + EF (98), антигенный компонент спор $(99,100)$ и компонент капсулы - поли-D- $\gamma$-глутаминовой кислоты B. anthracis (101-104); вакцины на основе rPA83, находящегося в смеси с другими компонентами, такими как рекомбинантный белок поверхностного S-слоя бактерии (105) или спорами B. anthracis $(106,107)$. Новый подход был использован при разработке вакцины на основе спор пробиотика Bacillus subtilis с использованием технологии, позволяющей экспрессировать с высокой эффективностью гетерологичный целевой белок - rPA83 в фазу споруляции с дальнейшим прикреплением или адсорбцией белка на поверхности споры. Безопасность и эффективность вакцины продемонстрирована при различных способах введения, включая пероральный, интраназальный и сублингвальный (107). В дополнение к этим стратегиям для повышения иммуногенности и стабильности вакцин на основе rPA83 или отдельных доменов РА исследуется возможность использования различных адъювантов $(74,108)$. Ряд новых адъювантов находятся на стадии клинических испытаний, и накапливаются данные об их эффективности по сравнению с гидроксидом алюминия, используемым во многих вакцинах (109). Одна из главных проблем при создании субъединичных вакцин на основе rPA83 - нестабильность этого белка. rPA83 содержит два сайта, чувствительных к протеолитическому расщеплению. Показано также, что нестабильность rPA83 связана со спонтанным дезамидированием нескольких остатков аспарагина в составе белка, причем скорость дезамидирования значительно увеличивается, когда гидроксид алюминия используется в качестве адъюванта. Исходя из ряда данных, опубликованных в последнее время, можно утверждать, что rPA83, 
адсорбированный на гидроксиде алюминия, нестабилен и теряет способность индуцировать нейтрализующие антитела при хранении (110-112). Новые адъювантные композиции, а также использование мутантных форм rPA83, устойчивых к протеолизу и дезамидированию, могут решить эту проблему. Подбор нового оптимального адъюванта и стабилизация молекулы rPA83 являются одним из основных направлений для разработки новой эффективной вакцины против сибирской язвы. В работе Е.M. Ryabchevskaya с соавт. (113) продемонстрирована возможность одновременного применения двух подходов для стабилизации rРА83 - посредством адсорбции rPA83 на поверхности частиц сферической формы на основе вируса растения и направленного мутагенеза сайтов, которые служат причиной дестабилизации белка. Таким образом, за прошедшие годы с развитием методов генной инженерии, разработки различных векторных платформ, ДНК-вакцин, а также адъювантных систем, используемых для повышения иммуногенности и стабильности субъединичных вакцин, есть все предпосылки для создания новых, более безопасных и эффективных вакцин против сибирской язвы.

Проведенный нами поиск научных публикаций, посвященных экспериментальным ветеринарным вакцинам с исследованиями на сельскохозяйственных животных, выявил всего несколько работ. Однако, по мнению многих авторов, методы и подходы, используемые для разработки вакцин медицинского назначения, оптимальны и при создании ветеринарных вакцин. В работе A. Fasanella c соавт. (71) rPA83 и мутантные формы летального фактора (mLF-Y728A; E735A) и отечного фактора (mEF-K346R) с инактивированной ферментативной активностью были успешно клонированы и экспрессированы в системе Esherichia coli. Две кандидатные вакцины - моновалентная, содержащая rPA83, и трехвалентная (TV), содержащая rPA83, $\mathrm{mLF}, \mathrm{mEF}$, были использованы для иммунизации кроликов в присутствии адъювантов Marcol 52 (ESSO) и Montane 80® (SEPPIC), обычно используемых в качестве адъювантов для ветеринарного применения. Новозеландские кролики, однократно иммунизированные подкожно rPA83 и TV, продуцировали высокий уровень антител против PA (rPA83 и TV вакцины), LF и EF (TV вакцина), и оба вакцинных препарата продемонстрировали $100 \%$ защиту кроликов, зараженных вирулентным штаммом B. anthracis 0843 (200LD50) через 1 нед после вакцинации. У кроликов, иммунизированных вакциной Sterne, выработка антител против PA, LF и EF была значительно ниже, чем индуцированная экспериментальными вакцинами, и при тестировании в тех же условиях эксперимента вакцина Sterne защищала только 80 \% кроликов, зараженных через 1 нед после вакцинации. Таким образом, обе кандидатные вакцины были эффективнее, чем вакцина Sterne. Другим преимуществом этих вакцин является возможность их одновременного использования с антибиотиками в связи с отсутствием живого патогена. Однако следует отметить, что преимущество трехвалентной вакцины по сравнению с вакциной на основе только одного антигена - rPA83 - в этих экспериментах не было показано. Более того, существуют данные, что использование каталитически инактивированных мутантов ЕF с одной точечной мутацией совместно с РА может быть небезопасно (114).

В работе S.M. Koehler с соавт. (115) иммуногенность и протективность двух рекомбинантных многокомпонентных вакцин изучалась на козах с использованием липопептидного адъюванта. В состав вакцин входили rPA и антигенный компонент спор BclA (bacillus collagen-like protein of anthracis), полученных в системе экспрессии E. coli, а также инактивированные формалином споры (FIS). Козы имеют чрезвычайно высокую 
восприимчивость к $B$. antracis. Козы, трехкратно иммунизированные подкожно препаратами rPA + rBclA или rPA + rBclA + FIS, продемонстрировали защиту (соответственно 50 \% и 80 \%) после заражения летальной дозой спор вирулентного штамма B. anthracis. Дальнейшие исследования этой же группы ученых показали, что иммунная сыворотка от коз, вакцинированных комбинациями rPA + rBclA + FIS и rPA + rBclA, способна защитить $\sim 70 \%$ мышей от заражения летальной дозой спор сибирской язвы (116). Таким образом, проведенные эксперименты продемонстрировали эффективность двух рекомбинантных вакцин против сибирской язвы и индукцию протективного иммунного ответа у вакцинированных коз. Предварительные данные серологических исследований на козах подтвердили надежность иммуногенности этих вакцин и при введении в сочетании с длительным приемом антибиотиков.

В настоящее время эта же научная группа продолжает изучения кандидатной вакцины на крупном рогатом скоте. B работе S. Jauro с соавт. (106) проводилось сравнение иммуногенности и протективной эффективности кандидатной вакцины на основе rPA83 в комбинации с инактивированными спорами (FIS) и с адъювантом, содержащим гидроксид алюминия (Emulsigen-D/Alhydrogel), и у вакцины на основе спор аттенуированного штамма Sterne 34F2. После вакцинации коров оценивали иммуногенность и протективность in vitro в токсин-нейтрализующем тесте и in vivo на модели мышей с пассивной иммунизацией. Показано, что титры антител и протективность у двух вакцин были одинаковы. Однако доказано, что в отличие от вакцины Sterne, кандидатная вакцина была высокоэффективна при одновременном использовании с антибиотиками (117).

Несколько групп исследователей используют различные подходы для получения rPA83 в растительной системе экспрессии (74). J. Gorantala с соавт. (118) была предпринята попытка разработать универсальную вакцину для перорального введения, подходящую как для ветеринарного использования, так и для людей. С этой целью для экспрессии rPA83 были получены трансгенные растения горчицы (Brassica juncea), листья и стебли которой могут быть использованы в свежем виде в пищу людьми и для кормления крупного рогатого скота. Кроме того, мука, полученная из B. juncea используется в качестве корма для крупного рогатого скота во многих странах (118). Наличие стандартных протоколов трансформации B. juncea, большая биомасса, длительная стабильность трансгена, безопасное хранение антигена в семенах свидетельствуют в пользу того, что трансгенные растения горчицы могут эффективно экспрессировать rPA83 и стать основой для создания вакцины против сибирской язвы. Было показано, что трансгенные растения $B$. јипсеа при многократном пероральном введении мышам в течение 1 мес с финальной бустерной дозой rPA83, полученного в E. coli (вводимого также перорально), в присутствии мукозольного адъюванта стимулировали как системный, так и мукозальные иммунные ответы, и 60 \% мышей выживали после введения летальной дозы B. anthracis (штамм Sterne). В контрольных экспериментах с использованием rPA83, полученного в E. coli, при пероральном введении (с помощью зонда) $80 \%$ мышей выживали после введения летальной дозы B. anthracis. Необходимость бустера (rPA83) могла объясняться тем, что уровень экспрессии белка в трансгенных растениях горчицы был невысоким и составлял 0,3-0,8 \% от общей массы растворимой фракции белка (118). По мнению авторов, необходимы дальнейшие исследования для улучшения экспрессии белка. В частности, предполагается создание транспластомных растений горчицы с 
интеграцией гена РА83 в хлоропластный геном. В этом же исследовании были получены транспластомные растения табака, в которых уровень экспрессии rРA83 составлял 2,5-4,0 \% от общей массы растворимой фракции растительного белка. Кроме того, авторы считают, что особенности пищеварительных процессов у жвачных животных могут способствовать эффективному воздействию антигена на лимфоидные ткани, связанные с кишечником, и таким образом усиливать иммунный ответ слизистой оболочки кишечника. Как уже упоминалось, споры после попадания в организм могут прорасти в вегетативную форму локально на первичных участках контакта патогена с хозяином, например в слизистой кишечника. Поэтому разработка ветеринарной рекомбинантной вакцины с пероральным введением рассматривается как важное и перспективное направление.

В другом исследовании были получены транспластомные растения табака, в которых уровень экспрессии rPA83 в зрелых листьях достигал $14,2 \%$ от общей массы растворимой фракции растительного белка. Расчеты показали, что один акр (0,405 га) посевов растений транспластомного табака, экспрессирующего rPA83, может производить до 360 млн доз вакцины против сибирской язвы (119). Экспрессия антигенов сибирской язвы с использованием растительной системой - перспективное направление для вакцинации жвачных животных, находящихся на свободном выпасе, и это направление, безусловно, требует дальнейшего развития.

Итак, особенности жизненного цикла и экологии возбудителя сибирской язвы свидетельствуют о том, что полностью искоренить это заболевания пока что невозможно. Основным способом борьбы с сибирской язвой служит вакцинация. Живые аттенуированные вакцины, применяемые в течение многих десятилетий, эффективны, но имеют ряд ограничений, в частности они несовместимы с приемом антибиотиков, которые необходимы как в периоды вспышек сибирской язвы, так и для лечения других заболеваний животных. Поэтому использование рекомбинантных вакцин, которые можно вводить совместно с антибиотиками, - крайне актуальный и, более того, фактически единственно перспективный способ улучшить эпизоотическую и эпидемическую ситуацию с этим опасным заболеванием. Основное направление при разработке современных вакцин против возбудителя сибирской язвы сфокусировано на создании рекомбинантых субъединичных вакцин, включающих последовательность протективного антигена (РА) - основного антигена токсина сибирской язвы. Безусловный приоритет, конечно, отдается созданию безопасных и эффективных вакцин для человека, но потенциально те же подходы и рекомбинантные антигены могут использоваться для иммунизации сельскохозяйственных животных. Рекомбинантные вакцины, в том числе для перорального введения, - это перспективное направление для развития ветеринарных вакцин. На сельскохозяйственных животных уже получены данные по эффективности кандидатных вакцин на основе rРА83 в смеси с инактивированными спорами Bacillus anthracis и доказано, что в отличие от вакцины Sterne кандидатная вакцина высокоэффективна при одновременном использовании с антибиотиками. Многообещающими представляются субъединичные вакцины на основе rPA83 - как векторные с экспрессией in vivo, так и на основе peкомбинантного антигена, полученного in vitro и стабилизированного без потери иммуногенности. По нашему мнению, также перспективны мутантные формы rPA83, устойчивые к протеолизу, в комбинации с новыми адъювантами и (или) платформами. Еще одно важное направление в развитии рекомбинантных ветеринарных вакцин, которому следует уделить вни- 


\title{
мание, - использование пробиотиков (Lactobacillus spp.) в качестве векто- ров для доставки антигена или для экспонирования антигена на поверхно- сти спор B. subtilis с возможностью перорального введения.
}

\author{
ФГБОУ ВО МГУ им. М.В. Ломоносова, \\ Биологический факультет, \\ 119234 Россия, г. Москва, Ленинские горы, 1, стр. 12, \\ e-mail: olgakond1@yandex.ru $₫$, nikitin@mail.bio.msu.ru, \\ katecat88@mail.ru, dgran98@gmail.com,okar@genebee.msu.ru
}

Поступила в редакцию 10 марта 2021 года

Sel'skokhozyaistvennaya biologiya [Agricultural Biology], 2021, V. 56, № 3, pp. 415-433

\section{ANTHRAX: LIFE CYCLE, MECHANISMS OF PATHOGENESIS AND PROSPECTS IN THE DEVELOPMENT OF VETERINARY VACCINES} (review)

\author{
O.A. Kondakova ${ }^{\bowtie}$, N.A. Nikitin, E.A. Evtushenko, D.L. Granovskiy, \\ J.G. Atabekov, O.V. Karpova
}

Lomonosov Moscow State University, Biological Faculty, str. 12, 1, Leninskie gory, Moscow, 119234 Russia, e-mail olgakond1@yandex.ru (corresponding author $\varangle$ ), nikitin@mail.bio.msu.ru, katecat88@mail.ru, dgran98@gmail.com, okar@genebee.msu.ru

ORCID:

Kondakova O.A. orcid.org/0000-0001-5134-6624

Nikitin N.A. orcid.org/0000-0001-9626-2336

Granovskiy D.L. orcid.org/0000-0003-0947-1784

Evtushenko E.A. orcid.org/0000-0002-0679-6818

Atabekov J.G. orcid.org/0000-0003-3407-4051

The authors declare no conflict of interests

Karpova O.V. orcid.org/0000-0002-0605-9033

Acknowledgements:

Supported financially by the Russian Science Foundation (Grant No. 18-14-00044)

Received March 10, 2021

doi: 10.15389/agrobiology.2021.3.415eng

\section{Abstract}

Anthrax is an acute especially dangerous disease of agricultural and wild animals, as well as humans. Anthrax is induced by the gram-positive spore-forming bacterium Bacillus anthracis. This infection is global, but the incidence rate of livestock and people varies depending on the environmental situation and the implementation of control strategies (C.J. Carlson et al., 2019). Historical and modern experience suggests that uncontrolled outbreaks of anthrax can have disastrous consequences. This review describes the life cycle of the pathogen, environmental features of the anthrax spread and mechanisms of pathogenesis. Given these factors we discuss the optimal strategies that have been developed over the years taking into account the cost and outcome for combating the dangerous infection. The timely disposal of dead animals and the vaccination of healthy livestock, used together, can effectively stop the spread of the disease. Thus, the development of highly effective, safe and lowcost vaccines is extremely relevant and, moreover, in fact the only promising method for improving the epizootic situation with this hazardous disease. Vaccination of farm animals for several decades has significantly reduced the risk of anthrax, but it is not mandatory in many countries and is often used only after onset of the disease, and not to prevent it. Despite a significant decrease in the incidence rate, the current situation with anthrax in the Russian Federation is characterized as unstable (A.G. Ryazanova et al., 2018; E.G. Simonova et al., 2018). Animal epizootics and human cases are still being recorded in the country due to the presence of natural soil reservoirs of the pathogen and incomplete coverage of vaccination for farm animals. Currently, only live attenuated vaccines are used to vaccinate animals. The review summarizes their effectiveness and safety, as well as the limitations associated with the use of attenuated vaccines. Although existing vaccines have been shown to be effective, they have several serious flaws. Certainly, the relevance of the development of more effective veterinary vaccines against anthrax, based on modern approaches, is fully justified. In particular, there is a need to design a veterinary vaccine that does not contain the pathogen in any form and is compatible with the use of antibiotics, which are necessary, both during the outbreak of anthrax and for regular use in the treatment of various animal diseases. The application of new approaches, the devising modern recombinant vaccines and the rejection of the use of pathogens in an attenuated form is an important and promising task. This review provides an analysis of studies on the development of new candidate vaccines against anthrax. The main attention is paid to the development of subunit vaccines using $B$. anthracis recombinant antigens obtained in various expression systems, including vaccines for oral administration and compatible with antibiotics.

Keywords: anthrax, Bacillus anthracis, veterinary vaccines, recombinant antigens 


\section{REFER E N C ES}

1. World Health Organization. Anthrax in humans and animals. 4th ed. Geneva, WHO Press, 2008.

2. Martin G.J., Friedlander A.M. Bacillus anthracis (anthrax). In: Mandell, Douglas, and Bennett's principles and practice of infectious diseases. G.L. Mandell, J.E. Bennett, R. Dolin (eds.). Philadelphia, Churchill Livingstone, 2010: 2715-2725.

3. Carlson C.J., Kracalik I.T., Ross N., Alexander K.A., Hugh-Jones M.E., Fegan M., Elkin B.T., Epp T., Shury T.K., Zhang W., Bagirova M., Getz W.M., Blackburn J.K. The global distribution of Bacillus anthracis and associated anthrax risk to humans, livestock and wildlife. Nature Microbiology, 2019, 4: 1337-1343 (doi:10.1038/s41564-019-0435-4).

4. Lindeque P.M., Turnbull P.C. Ecology and epidemiology of anthrax in the Etosha National Park, Namibia. Onderstepoort Journal of Veterinary Research, 1994, 61: 71-83.

5. Hugh-Jones M.E., de Vos V. Anthrax and wildlife. Revue Scientifique et Technique, 2002, 21(2): 359-83 (doi: 10.20506/rst.21.2.1336).

6. Hoffmann C., Zimmermann F., Biek R., Kuehl H., Nowak K., Mundry R., Agbor A., Angedakin S, Arandjelovic M., Blankenburg A., Brazolla G., Corogenes K., Couacy-Hymann E., Deschner T., Dieguez P., Dierks K., Düx A., Dupke S., Eshuis H., Formenty P., Yuh Y.G., Goedmakers A., Gogarten J.F., Granjon A.C., McGraw S., Grunow R., Hart J., Jones S., Junker J., Kiang J., Langergraber K., Lapuente J., Lee K., Leendertz S.A., Léguillon F., Leinert V., Löhrich T., Marrocoli S., Mätz-Rensing K., Meier A., Merkel K., Metzger S., Murai M., Niedorf S., De Nys H., Sachse A., van Schijndel J., Thiesen U., Ton E., Wu D., Wieler L.H., Boesch C., Klee S.R., Wittig R.M., Calvignac-Spencer S., Leendertz F.H. Persistent anthrax as a major driver of wildlife mortality in a tropical rainforest. Nature, 2017, 548(7665): 82-86 (doi: 10.1038 /nature23309).

7. Cossaboom C.M., Khaiseb S., Haufiku B., Katjiuanjo P., Kannyinga A., Mbai K., Shuro T., Hausiku J., Likando A., Shikesho R., Nyarko K., Miller L.A., Agolory S., Vieira A.R., Salzer J.S., Bower W.A., Campbell L., Kolton C.B., Marston C., Gary J., Bollweg B.C., Zaki S.R., Hoffmaster A., Walke H. Anthrax epizootic in wildlife, Bwabwata National Park, Namibia, 2017. Emerging Infectious Diseases, 2019, 25(5): 947-950 (doi: 10.3201/eid2505.180867).

8. Van Ness G.B. Ecology of anthrax. Science, 1971, 172: 1303-1307 (doi: 10.1126/science.172.3990.1303).

9. Joyner T.A., Lukhnova L., Pazilov Y., Temiralyeva G., Hugh-Jones M.E., Aikimbayev A., Blackburn J.K. Modeling the potential distribution of Bacillus anthracis under multiple climate change scenarios for Kazakhstan. PLoS ONE, 2010, 5(3): e9596 (doi: 10.1371/journal.pone.0009596).

10. Norris M.H., Blackburn J.K. Linking geospatial and laboratory sciences to define mechanisms behind landscape level drivers of anthrax outbreaks. International Journal of Environmental Research, 2019, 16(19): 3747 (doi: 10.3390/ijerph16193747).

11. Simonova E.G., Kartavaya S.A., Titkov A.V., Loktionova M.N., Raichich S.R., Tolpin V.A., Lupyan E.A., Platonov A.E. Problemy osobo opasnykh infektsii, 2017, 1: 89-93 (doi: 10.21055/0370-1069-2017-1-89-93) (in Russ.).

12. Walsh M.G., Smalen A.W., Mor S.M. Climatic influence on anthrax suitability in warming northern latitudes. Scientific Reports, 2018, 8: 9269 (doi: 10.1038/s41598-018-27604-w).

13. Beyer W., Turnbull P.C.B. Anthrax in animals. Molecular Aspects of Medicine, 2009, 30(6): 481489 (doi: 10.1016/j.mam.2009.08.004).

14. Sterne M. The use of anthrax vaccines prepared from avirulent (uncapsulated) variants of Bacillus anthracis. Onderstepoort Journal of Veterinary Science and Animal Industry, 1939, 13: 307-312.

15. Felix J.B., Chaki S.P., Ficht T.A., Rice-Ficht A.C., Cook W. Bacillus anthracis Sterne Strain 34F2 vaccine antibody dose response by subcutaneous and oral administration. Poultry, Fisheries \& Wildlife Sciences, 2019, 7: 206 (doi: 10/35248/2375-446X.19.7.206).

16. Cherkasskii B.L. Epidemiologiya i profilaktika sibirskoi yazvy [Epidemiology and prevention of anthrax]. Moscow, 2002 (in Russ.).

17. Arutyunov Yu.I. Universum: Meditsina i farmakologiya: elektronnyi nauchnyi zhurnal, 2013, 1(1). Available: http://7universum.com/ru/med/archive/item/324. Accessed: 23.12 .2019 (in Russ.).

18. Dragon D.C., Elkin B.T., Nishi J.S., Ellsworth T.R. A review of anthrax in Canada and implications for research on the disease in northern bison. Journal of Applied Microbiology, 1999, 87: 208213 (doi: 10.1046/j.1365-2672.1999.00872.x).

19. Blackburn J.K., Van Ert M., Mullins J.C., Hadfield T.L., Hugh-Jones M.E. The necrophagous fly anthrax transmission pathway: empirical and genetic evidence from wildlife epizootics. VectorBorne and Zoonotic Diseases, 2014, 14(8): 576-83 (doi: 10.1089/vbz.2013.1538).

20. Basson L., Hassim A., Dekker A., Gilbert A., Beyer W., Rossouw J., Van Heerden H. Blowflies as vectors of Bacillus anthracis in the Kruger National Park. Koedoe, 2018, 60(1): a1468 (doi: 10.4102/koedoe.v60i1.1468).

21. Munang'andu H.M., Banda F., Siamudaala V.M., Munyeme M., Kasanga C.J., Hamududu B. The effect of seasonal variation on anthrax epidemiology in the upper Zambezi floodplain of western 
Zambia. Journal of Veterinary Science, 2012, 13(3): 293-298 (doi: 10.4142/jvs.2012.13.3.293).

22. Turner W., Kausrud K., Beyer W., Easterday W., Barandongo Z., Blaschke E., Blaschke E., Cloete C.C., Lazak J., Van Ert M.N., Ganz H.H., Turnbull P.C.B., Stenseth N.C., Getz W.M. Lethal exposure: An integrated approach to pathogen transmission via environmental reservoirs. Scientific Reports, 2016, 6: 27311 (doi: 10.1038/srep27311).

23. Hugh-Jones M., Blackburn J. The ecology of Bacillus anthracis. Molecular Aspects of Medicine, 2009, 30: 356-367 (doi: 10.1016/j.mam.2009.08.003).

24. Kolonin G.V. Russkii ornitologicheskii zhurnal, 2017, 26(1397): 327-329 (in Russ.).

25. Dey R., Hoffman P.S., Glomski I.J. Germination and amplification of anthrax spores by soildwelling amoebas. Applied and Environmental Microbiology, 2012, 78(22): 8075-8081 (doi: 10.1128/AEM.02034-12).

26. Saile E., Koehler T.M. Bacillus anthracis multiplication, persistence, and genetic exchange in the rhizosphere of grass plants. Applied and Environmental Microbiology, 2006, 72(5): 3168-3174 (doi: 10.1128/AEM.72.5.3168-3174.2006).

27. Schuch R., Fischetti V.A. The secret life of the anthrax agent Bacillus anthracis: bacteriophagemediated ecological adaptations. PLoS ONE, 2009, 4: e6532 (doi: 10.1371/journal.pone.0006532).

28. U.S EPA. Environmental persistence of vegetative Bacillus anthracis and Yersinia pestis. U.S. Environmental Protection Agency, Washington, DC, EPA/600/R-14/150, 2014.

29. Ryazanova A.G., Semenova O.V., Eremenko E.I., Aksenova L.YU., Buravtseva N.P., Golovinskaya T.M., Kulichenko A.N. Problemy osobo opasnykh infektsii, 2018, 1: 63-65 (in Russ.).

30. Kartavaya S.A., Simonova E.G., Loktionova M.N., Kolganova O.A., Ladnyi V.I., Raichich S.R. Gigiena i sanitariya, 2016, 95(7): 601-606 (in Russ.).

31. Simonova E.G., Kartavaya S.A., Raichich S.R., Loktionova M.N., SHabeikin A.A. Epidemiologiya i vaktsinoprofilaktika, 2018, 17(2): 57-62 (in Russ.).

32. Cherkasskii B.L. Kadastr statsionarno neblagopoluchnykh po sibirskoi yazve punktov Rossiiskoi Federatsii [Cadastre of permanently anthrax-problematic sites of the Russian Federation]. Moscow, 2005 (in Russ.).

33. Gavrilov V.A., Gryazneva T.N., Seliverstrov V.V. Veterinariya, zootekhniya i biotekhnologiya, 2017, 8: 17-22 (in Russ.).

34. Mwakapeje E.R., Høgset S., Fyumagwa R., Nonga H.E., Mdegela R.H., Skjerve E. Anthrax outbreaks in the humans - livestock and wildlife interface areas of Northern Tanzania: a retrospective record review 2006-2016. BMC Public Health, 2018, 18(1): 106 (doi: 10.1186/s12889-017-5007-z).

35. Popova A.Yu., Demina Yu.V., Ezhlova E.B., Kulichenko A.N., Ryazanova A.G., Maleev V.V., Ploskireva A.A., Dyatlov I.A., Timofeev V.S., Nechepurenko L.A., Khar'kov V.V. Problemy osobo opasnykh infektsii, 2016, 4: 42-46 (doi: 10.21055/0370-1069-2016-4-42-46) (in Russ.).

36. Croicu A.M. An optimal control model to reduce and eradicate anthrax disease in herbivorous animals. Bulletin of Mathematical Biology, 2019, 81(1): 235-255 (doi: 10.1007/s11538-018-0525-0).

37. Makino S., Watarai M., Cheun H.I., Shirahata T., Uchida I. Effect of the lower molecular capsule released from the cell surface of Bacillus anthracis on the pathogenesis of anthrax. Journal of Infectious Diseases, 2002, 186(2): 227-233 (doi: 10.1086/341299).

38. Sharma S., Bhatnagar R., Gaur D. Bacillus anthracis poly- $\gamma-D$-glutamate capsule inhibits opsonic phagocytosis by impeding complement activation. Frontiers in Immunology, 2020, 11: 462 (doi: 10.3389/fimmu.2020.00462).

39. Okinaka R.T., Cloud K., Hampton O., Hoffmaster A.R., Hill K.K., Keim P., Koehler T.M., Lamke G., Kumano S., Mahillon J., Manter D., Martinez Y., Ricke D., Svensson R., Jackson P.J. Sequence and organization of pXO1, the large Bacillus anthracis plasmid harboring the anthrax toxin genes. Journal of Bacteriology, 1999, 181(20): 6509-6515.

40. Liu S., Moayeri M., Leppla S.H. Anthrax lethal and edema toxins in anthrax pathogenesis. Trends in Microbiology, 2014, 22(6): 317-325 (doi: 10.1016/j.tim.2014.02.012).

41. Deuquet J., Lausch E., Superti-Furga A., van der Goot F.G. The dark sides of capillary morphogenesis gene 2. EMBO Journal, 2012, 31(1): 3-13 (doi: 10.1038/emboj.2011.442).

42. Sun J., Jacquez P. Roles of Anthrax Toxin Receptor 2 in anthrax toxin membrane insertion and pore formation. Toxins, 2016, 8(2): 34 (doi: 10.3390/toxins8020034).

43. Storm L., Bikker F.J., Nazmi K., Hulst A.G., der Riet-Van Oeveren D.V., Veerman E.C.I., Hays J.P., Kaman W.E. Anthrax protective antigen is a calcium-dependent serine protease. Virulence, 2018, 9(1): 1085-1091 (doi: 10.1080/21505594.2018.1486139).

44. Bann J.G. Anthrax toxin protective antigen--insights into molecular switching from prepore to pore. Protein Science, 2012, 21(1): 1-12 (doi: 10.1002/pro.752).

45. Jiang J., Pentelute B.L., Collier R.J., Zhou Z.H. Atomic structure of anthrax PA pore elucidates toxin translocation. Nature, 2015, 521(7553): 545-549 (doi: 10.1038/nature 14247).

46. Hardenbrook N.J., Liu S., Zhou K., Ghosal K., Zhou Z.H., Krantz B.A. Atomic structures of anthrax toxin protective antigen channels bound to partially unfolded lethal and edema factors. Nature Communications, 2020, 11: 840 (doi: 10.1038/s41467-020-14658-6).

47. Alameh S., Bartolo G., O’Brien S., Henderson E.A., Gonzalez L.O., Hartmann S., Klimko C.P., 
Shoe J.L., Cote C.K., Grill L.K., Levitin A. Anthrax toxin component, Protective Antigen, protects insects from bacterial infections. PLoS Pathogens, 2020, 16(8): e1008836 (doi: 10.1371/journal.ppat.1008836).

48. Duesbery N.S., Webb C.P., Leppla S.H., Gordon V.M., Klimpel K.R., Copeland T.D., Ahn N.G., Oskarsson M.K., Fukasawa K., Paull K.D., Vande Woude G.F. Proteolytic inactivation of MAP-kinase-kinase by anthrax lethal factor. Science, 1998, 280: 734-737 (doi: 10.1126/science.280.5364.734).

49. Vitale G., Bernardi L., Napolitani G., Mock M., Montecucco C. Susceptibility of mitogenactivated protein kinase kinase family members to proteolysis by anthrax lethal factor. Biochemical Journal, 2000, 352: 739-745 (doi: 10.1042/bj352073938).

50. Pellizzari R., Guidi-Rontani C., Vitale G., Mock M., Montecucco C. Anthrax lethal factor cleaves MKK3 in macrophages and inhibits the LPS/IFNgamma-induced release of NO and TNFalpha. FEBS Letters, 1999, 462: 199-204 (doi: 10.1016/S0014-5793(99)01502-1).

51. Leppla S.H. Anthrax toxin edema factor: a bacterial adenylate cyclase that increases cyclic AMP concentrations of eukaryotic cells. Proceedings of the National Academy of Sciences, 1982, 79: 3162-3166 (doi: 10.1073/pnas.79.10.3162).

52. Bromberg-White J., Lee C.S., Duesbery N. Consequences and utility of the zinc-dependent metalloprotease activity of anthrax lethal toxin. Toxins (Basel), 2010, 2(5): 1038-1053 (doi: 10.3390/toxins2051038).

53. Tang W.J., Guo Q. The adenylyl cyclase activity of anthrax edema factor. Molecular Aspects of Medicine, 2009, 30(6): 423-430 (doi: 10.1016/j.mam.2009.06.001).

54. Jara G.E., Martínez L. Anthrax edema factor: an ion-adaptive mechanism of catalysis with increased transition-state conformational flexibility. Journal of Physical Chemistry B, 2016, 120: 6504-6514 (doi: 10.1021/acs.jpcb.6b02527).

55. Cote C.K., Rossi C.A., Kang A.S., Morrow P.R., Lee J.S., Welkos S.L. The detection of protective antigen (PA) associated with spores of Bacillus anthracis and the effects of anti-PA antibodies on spore germination and macrophage interactions. Microbial Pathogenesis, 2005, 38: 209-225 (doi: 10.1016/j.micpath.2005.02.001).

56. Liu S., Zhang Y., Moayeri M., Liu J., Crown D., Fattah R.J., Wein A.N., Yu Z.-X., Finkel T., Leppla S.H. Key tissue targets responsible for anthrax-toxin-induced lethality. Nature, 2013, 501: 63-68 (doi: 10.1038/nature12510).

57. Liu S., Schubert R.L., Bugge T.H., Leppla S.H. Anthrax toxin: structures, functions and tumour targeting. Expert Opin. Biol. Ther., 2003, 3: 843-853 (doi: 10.1517/14712598.3.5.843).

58. Hutt J.A., Lovchik J.A., Drysdale M., Sherwood R.L., Brasel T., Lipscomb M.F., Lyons C.R. Lethal factor, but not edema factor, is required to cause fatal anthrax in cynomolgus macaques after pulmonary spore challenge. The American Journal of Pathology, 2014, 184(12): 3205-3216 (doi: 10.1016/j.ajpath.2014.08.008).

59. Patel V.I., Booth J.L., Dozmorov M., Brown B.R., Metcalf J.P. Anthrax edema and lethal toxins differentially target human lung and blood phagocytes. Toxins (Basel), 2020, 12(7): 464 (doi: 10.3390/toxins12070464).

60. Abrami L., Brandi L., Moayeri M., Brown M.J., Krantz B.A., Leppla S.H., van der Goot F.G. Hijacking multivesicular bodies enables long-term and exosome-mediated long-distance action of anthrax toxin. Cell Reports, 2013, 5(4): 986-996 (doi: 10.1016/j.celrep.2013.10.019).

61. Hambleton P., Carman J.A., Melling J. Anthrax: the disease in relation to vaccines. Vaccine, 1984, 2(2): 125-132 (doi: 10.1016/0264-410x(84)90003-3).

62. Scorpio A., Blank T.E., Day W.A., Chabot D.J. Anthrax vaccines: Pasteur to the present. Cellular and Molecular Life Sciences, 2006, 63: 2237-2248 (doi: 10.1007/s00018-006-6312-3).

63. Thorkildson P., Kinney H.L., AuCoin D.P. Pasteur revisited: an unexpected finding in Bacillus anthracis vaccine strains. Virulence, 2016, 7(5): 506-507 (doi: 10.1080/21505594.2016.1186325).

64. Liang X., Zhang H., Zhang E., Wei J., Li W., Wang B., Dong S., Zhu J. Identification of the pXO1 plasmid in attenuated Bacillus anthracis vaccine strains. Virulence, 2016, 7(5): 578-586 (doi: 10.1080/21505594.2016.1164366).

65. Fasanella A., Losito S., Trotta T., Adone R., Massa S., Ciuchini F., Chiocco D. Detection of anthrax vaccine virulence factors by polymerase chain reaction. Vaccine, 2001, 19: 4214-4218 (doi: 10.1016/s0264-410x(01)00159-1).

66. Harrington R., Ondov B.D., Radune D., Friss M.B., Klubnik J., Diviak L., Hnath J., Cendrowski S.R., Blank T.E., Karaolis D., Friedlander A.M., Burans J.P., Rosovitz M.J., Treangen T., Phillippy A.M., Bergman N.H. Genome sequence of the attenuated Carbosap vaccine strain of $B a-$ cillus anthracis. Genome Announcements, 2013, 1(1): e00067-12 (doi: 10.1128/genomeA.00067-12).

67. Cataldi A., Mock M., Bentancor L. Characterization of Bacillus anthracis strains used for vaccination. Journal of Applied Microbiology, 2000, 88: 648-654 (doi: 10.1046/j.1365-2672.2000.01005.x).

68. Wobeser B.K. Anthrax vaccine associated deaths in miniature horses. Canadian Veterinary Journal, 2015, 56(4): 359-360.

69. Cartwright M.E., McChesney A.E., Jones R.L. Vaccination-related anthrax in three llamas. 
Journal of the American Veterinary Medical Association, 1987, 191(6): 715-716.

70. Felix J.B., Chaki S.P., Xu Y., Ficht T.A., Rice-Ficht A.C., Cook W.E. Protective antibody response following oral vaccination with microencapsulated Bacillus anthracis Sterne strain 34F2 spores. npj Vaccines, 2020, 5: 59 (doi: 10.1038/s41541-020-0208-3).

71. Fasanella A., Tonello F., Garofolo G., Muraro L, Carattoli A., Adone R., Montecucco C. Protective activity and immunogenicity of two recombinant anthrax vaccines for veterinary use. Vaccine, 2008, 26(45): 5684-5688 (doi: 10.1016/j.vaccine.2008.08.026).

72. Turnbull P.C.B. Anthrax vaccines: past, present and future. Vaccine, 1991, 9: 533-539 (doi: 10.1016/0264-410X(91)90237-Z).

73. Jorge S., Dellagostin O.A. The development of veterinary vaccines: a review of traditional methods and modern biotechnology approaches. Biotechnology Research and Innovation, 2017, 1(1): 6-13 (doi: 10.1016/j.biori.2017.10.001).

74. Kondakova O.A., Nikitin N.A., Evtushenko E.A., Ryabchevskaya E.M., Atabekov J.G., Karpova O.V. Vaccines against anthrax based on recombinant protective antigen: problems and solutions. Expert Review of Vaccines, 2019, 18(8): 813-828 (doi: 10.1080/14760584.2019.1643242).

75. Turnbull P.C.B., Leppla S.H., Broster M.G., Quinn C.P., Melling J. Antibodies to anthrax toxin in humans and guinea pigs and their relevance to protective immunity. Medical Microbiology and Immunology, 1988, 177: 293-303 (doi: 10.1007/bf00189414).

76. Ndumnego O.C., Kцhler S.M., Craford J., van Heerden H., Beyer W. Comparative analysis of the immunologic response induced by the Sterne 34F2 live spore Bacillus anthracis vaccine in a ruminant model. Veterinary Immunology and Immunopathology, 2016, 178: 14-21 (doi: 10.1016/j.vetimm.2016.06.005).

77. Phaswana P.H., Ndumnego O.C., Koehler S.M., Beyer W., Crafford J.E., van Heerden H. Use of the mice passive protection test to evaluate the humoral response in goats vaccinated with Sterne 34F2 live spore vaccine. Veterinary Research, 2017, 48(1): 46 (doi: 10.1186/s13567-0170451-4).

78. Zhang J., Jex E., Feng T., Sivko G.S., Baillie L.W., Goldman S., Van Kampen K.R, Tang D.C. An adenovirus-vectored nasal vaccine confers rapid and sustained protection against anthrax in a single-dose regimen. Clinical and Vaccine Immunology, 2013, 20(1): 1-8 (doi: 10.1128/CVI.00280-12).

79. Krishnan V., Andersen B.H., Shoemaker C., Sivko G.S., Tordoff K.P., Stark G.V., Zhang J., Feng T., Duchars M., Roberts M.S. Efficacy and immunogenicity of single-dose AdVAV intranasal anthrax vaccine compared to anthrax vaccine absorbed in an aerosolized spore rabbit challenge model. Clinical and Vaccine Immunology, 2015, 22(4): 430-439 (doi: 10.1128/CVI.00690-14).

80. Mohamadzadeh M., Duong T., Sandwick S.J., Hoover T., Klaenhammer T.R. Dendritic cell targeting of Bacillus anthracis protective antigen expressed by Lactobacillus acidophilus protects mice from lethal challenge. PNAS, 2009, 106(11): 4331-4336 (doi: 10.1073/pnas.0900029106).

81. Mohamadzadeh M., Durmaz E., Zadeh M., Pakanati K.C., Gramarossa M., Cohran V., Klaenhammer T.R. Targeted expression of anthrax protective antigen by Lactobacillus gasseri as an anthrax vaccine. Future Microbiology, 2010, 5(8): 1289-1296 (doi: 10.2217/fmb.10.78).

82. Osorio M., Wu Y., Singh S., Merkel T.J., Bhattacharyya S., Blake M.S., Kopecko D.J. Anthrax protective antigen delivered by Salmonella enterica serovar Typhi Ty21a protects mice from a lethal anthrax spore challenge. Infection and Immunity, 2009, 77(4): 1475-1482 (doi: 10.1128/IAI.00828-08).

83. Ramirez K., Ditamo Y., Galen J.E., Baillie L.W., Pasetti M.F. Mucosal priming of newborn mice with S. Typhi Ty21a expressing anthrax protective antigen (PA) followed by parenteral PA-boost induces $\mathrm{B}$ and $\mathrm{T}$ cell-mediated immunity that protects against infection bypassing maternal antibodies. Vaccine, 2010, 28(37): 6065-6075 (doi: 10.1016/j.vaccine.2010.06.089).

84. Sim B.K.L., Li M., Osorio M., Wu Y., Wai T.T., Peterson J.W., James E.R., Chakravarty S., Gao L., Xu R., Natasha K.C., Stafford R.E., Lawrence W.S., Yeager L.F., Peel J.E., Sivasubramani S.K., Ashok K., Chopra A.K., Filippova S., Hoffman S.L. Protection against inhalation anthrax by immunization with Salmonella enterica serovar Typhi Ty21a stably producing protective antigen of Bacillus anthracis. npj Vaccines, 2017, 2: 17 (doi: 10.1038/s41541017-0018-4).

85. Donate A., Heller R. Assessment of delivery parameters with the multi-electrode array for development of a DNA vaccine against Bacillus anthracis. Bioelectrochemistry, 2013, 94: 1-6 (doi: 10.1016/j.bioelechem.2013.04.004).

86. Kim N.Y., Chang D.S., Kim Y., Kim C.H., Hur G.H., Yang J.M., Shin S. Enhanced immune response to DNA vaccine encoding Bacillus anthracis PA-D4 protects mice against anthrax spore challenge. PLoS ONE, 2015, 10(10): e0139671 (doi: 10.1371/journal.pone.0139671).

87. Köhler S.M., Baillie L.W., Beyer W. BclA and toxin antigens augment each other to protect NMRI mice from lethal Bacillus anthracis challenge. Vaccine, 2015, 33(24): 2771-2777 (doi: 10.1016/j.vaccine.2015.04.049).

88. Brown B.K., Cox J., Gillis A., VanCott T.C., Marovich M., Milazzo M., Antonille T.S., 
Wieczorek L, McKee K.T. Jr., Metcalfe K., Mallory R.M., Birx D., Polonis V.R., Robb M.L. Phase I study of safety and immunogenicity of an Escherichia coli-derived recombinant protective antigen (rPA) vaccine to prevent anthrax in adults. PLoS ONE, 2010, 5(11): e13849 (doi: 10.1371/journal.pone.0013849).

89. Bellanti J.A., Lin F.Y., Chu C., Shiloach J., Leppla S.H., Benavides G.A., Karpas A., Moayeri M., Guo C., Robbins J.B., Schneerson R. Phase I study of a recombinant mutant protective antigen of Bacillus anthracis. Clinical and Vaccine Immunology, 2012, 19(2): 140-145 (doi: 10.1128/CVI.05556-11).

90. Chun J.H., Choi O.J., Cho M.H., Hong K.J., Seong W.K., Oh H.B., Rhie G.E. Serological correlate of protection in Guinea pigs for a recombinant protective antigen anthrax vaccine produced from bacillus brevis. Osong public health and research perspectives, 2012, 3(3): 170-176 (doi: 10.1016/j.phrp.2012.07.006).

91. Reed M.D., Wilder J.A., Mega W.M., Hutt J.A., Kuehl P.J., Valderas M.W., Chew L.L., Liang B.C., Squires C.H. Immunization with a recombinant, Pseudomonas fluorescens-expressed, mutant form of Bacillus anthracis-derived protective antigen protects rabbits from anthrax infection. PloS ONE, 2015, 10(7): e0130952 (doi: 10.1371/journal.pone.0130952).

92. Mamedov T., Chichester J.A., Jones R.M., Ghosh A., Coffin M.V., Herschbach K., Prokhnevsky A.I., Streatfield S.J., Yusibov V. Production of functionally active and immunogenic nonglycosylated protective antigen from Bacillus anthracis in Nicotiana benthamiana by co-expression with peptide-N-glycosidase F (PNGase F) of Flavobacterium meningosepticum. PLoS ONE, 2016, 11(4): e0153956 (doi: 10.1371/journal.pone.0153956).

93. Li Q., Peachman K.K., Sower L., Leppla S.H., Shivachandra S.B., Matyas G.R., Peterson JW., Alving C.R., Rao M., Rao V.B. Anthrax LFn-PA hybrid antigens: biochemistry, immunogenicity, and protection against lethal ames spore challenge in rabbits. The Open Vaccine Journal, 2009, 2: 92-99 (doi: 10.2174/1875035400902010092).

94. Wu G., Hong Y., Guo A., Feng C., Cao S., Zhang C.C., Shi R., Tan Y., Liu Z. A chimeric protein that functions as both an anthrax dual-target antitoxin and a trivalent vaccine. Antimicrobial Agents and Chemotherapy, 2010, 54(11): 4750-4757 (doi: 10.1128/AAC.00640-10).

95. Baillie L.W., Huwar T.B., Moore S., Mellado-Sanchez G., Rodriguez L., Neeson B.N., FlickSmith H.C., Jenner D.C., Atkins H.S., Ingram R.J., Altmann D.M., Nataro J.P., Pasetti M.F. An anthrax subunit vaccine candidate based on protective regions of Bacillus anthracis protective antigen and lethal factor. Vaccine, 2010, 28(41): 6740-6748 (doi: 10.1016/j.vaccine.2010.07.075).

96. Suryanarayana N., Verma M., Thavachelvam K., Saxena N., Mankere B., Tuteja U., Hmuaka V. Generation of a novel chimeric PALFn antigen of Bacillus anthracis and its immunological characterization in mouse model. Appl. Microbiol. Biotechnol., 2016, 100(19): 8439-8451 (doi: 10.1007/s00253-016-7684-4).

97. Varshney A., Kumar M., Nagar D.P., Pal V., Goel A.K. Development of a novel chimeric PA-LF antigen of Bacillus anthracis, its immunological characterization and evaluation as a future vaccine candidate in mouse model. Biologicals, 2019, 61: 38-43 (doi: 10.1016/j.biologicals.2019.07.004).

98. Aggarwal S., Somani V.K., Gupta S., Garg R., Bhatnagar R. Development of a novel multiepitope chimeric vaccine against anthrax. Medical Microbiology and Immunology, 2019, 208: 185-195 (doi: 10.1007/s00430-019-00577-x).

99. Majumder S., Das S., Somani V., Makam S.S., Kingston J.J., Bhatnagar R. A bivalent protein r$\mathrm{PB}$, comprising PA and BclA immunodominant regions for comprehensive protection against Bacillus anthracis. Scientific Reports, 2018, 8(1): 7242 (doi: 10.1038/s41598-018-25502-9).

100. Majumder S., Das S., Somani V.K., Makam S.S., Kingston J.J., Bhatnagar R. A bivalent protein r-PAbxpB comprising PA Domain IV and Exosporium Protein BxpB confers protection against B. anthracis spores and toxin. Frontiers in Immunology, 2019, 10: 498 (doi: 10.3389/fimmu.2019.00498).

101. Lee D.Y., Chun J.H., Ha H.J., Park J., Kim B.S., Oh H.B., Rhie G.E. Poly-gamma-d-glutamic acid and protective antigen conjugate vaccines induce functional antibodies against the protective antigen and capsule of Bacillus anthracis in guinea-pigs and rabbits. FEMS Immunol. Med. Microbiol., 2009, 57(2): 165-172 (doi: 10.1111/j.1574-695X.2009.00595.x).

102. Candela T., Dumetz F., Tosi-Couture E., Mock M., Goossens P.L., Fouet A. Cell-wall preparation containing poly- $\gamma$-D-glutamate covalently linked to peptidoglycan, a straightforward extractable molecule, protects mice against experimental anthrax infection. Vaccine, 2012, 31(1): 171-175 (doi: 10.1016/j.vaccine.2012.10.071).

103. Garufi G., Wang Y.T., Oh S.Y., Maier H., Missiakas D.M., Schneewind O. Sortase-conjugation generates a capsule vaccine that protects guinea pigs against Bacillus anthracis. Vaccine, 2012, 30(23): 3435-3444 (doi: 10.1016/j.vaccine.2012.03.023).

104. Chen Z., Schneerson R., Lovchik J.A., Dai Z., Kubler-Kielb J., Agulto L., Leppla S.H., Purcell R.H. Bacillus anthracis capsular conjugates elicit chimpanzee polyclonal antibodies that protect mice from pulmonary anthrax. Clinical and Vaccine Immunology, 2015, 22(8): 902-908 (doi: 10.1128/CVI.00137-15). 
105. Kumar M., Puranik N., Varshney A., Tripathi N., Pal V., Goel A.K. BA3338, a surface layer homology domain possessing protein augments immune response and protection efficacy of protective antigen against Bacillus anthracis in mouse model. Journal of Applied Microbiology, 2020, 129(2): 443-452 (doi: 10.1111/jam.14624).

106. Jauro S., Ndumnego O.C., Ellis C., Buys A., Beyer W., Heerden H.V. Immunogenicity of nonliving anthrax vaccine candidates in cattle and protective efficacy of immune sera in A/J mouse model compared to the Sterne live spore vaccine. Pathogens, 2020, 9(7): 557 (doi: 10.3390/pathogens9070557).

107. Oh Y., Kim J.A., Kim C.H., Choi S.K., Pan J. Bacillus subtilis spore vaccines displaying protective antigen induce functional antibodies and protective potency. BMC Veterinary Research, 2020, 16: 259 (doi: 1186/s12917-020-02468-3).

108. Liu K., Yin Y, Zhang J., Zai X., Li R., Ma H., Xu J., Shan J., Chen W. Polysaccharide PCP-I isolated from Poria cocos enhances the immunogenicity and protection of an anthrax protective antigen-based vaccine. Human Vaccines \& Immunotherapeutics, 2020, 16(7): 1699-1707 (doi: 10.1080/21645515.2019.1675457).

109. Weir G.M., MacDonald L.D., Rajagopalan R., Sivko G.S., Valderas M.W., Rayner J., Berger B.J., Sammatur L., Stanford M.M. Single dose of DPX-rPA, an enhanced-delivery anthrax vaccine formulation, protects against a lethal Bacillus anthracis spore inhalation challenge. npj Vaccines, 2019, 4: 6 (doi: 10.1038/s41541-019-0102-z).

110. Wagner L., Verma A., Meade B.D., Reiter K., Narum D.L., Brady R.A., Little S.F., Burns D.L. Structural and immunological analysis of anthrax recombinant protective antigen adsorbed to aluminum hydroxide adjuvant. Clinical and Vaccine Immunology, 2012, 19: 1465-1473 (doi: 10.1128/CVI.00174-12).

111. Domínguez-Castillo R.I., Verma A., Amador-Molina J.C., Sirota L., Arciniega J.L. Ability of ELISA and a toxin neutralization assay to detect changes in immunogenicity of a recombinant Bacillus anthracis protective antigen vaccine upon storage. Biologicals, 2013, 41(2): 111-114 (doi: 10.1016/j.biologicals.2012.10.002).

112. D’Souza A.J., Mar K.D., Huang J., Majumdar S., Ford B.M., Dyas B., Ulrich R.G., Sullivan V.J. Rapid deamidation of recombinant protective antigen when adsorbed on aluminum hydroxide gel correlates with reduced potency of vaccine. Journal of Pharmaceutical Sciences, 2013, 102(2): 454461 (doi: 10.1002/jps.23422).

113. Ryabchevskaya E.M., Evtushenko E.A., Granovskiy D.L., Ivanov P.A., Atabekov J.G., Kondakova O.A., Nikitin N.A., Karpova O.V. Two approaches for the stabilization of Bacillus anthracis recombinant protective antigen. Human Vaccines \& Immunotherapeutics, 2020, 17(2): 560-565 (doi: 10.1080/21645515.2020.1772632).

114. Zhao T., Zhao X., Liu J., Meng Y., Feng Y., Fang T., Zhang J., Yang X., Li J., Xu J., Chen W. Diminished but not abolished effect of two His351 mutants of anthrax edema factor in a murine model. Toxins (Basel), 2016, 8(2): 35 (doi: 10.3390/toxins8020035).

115. Koehler S.M., Buyuk F., Celebi O., Demiraslan H., Doganay M., Sahin M., Moehring J., Ndumnego O.C., Otlu S., van Heerden H., Beyer W. Protection of farm goats by combinations of recombinant peptides and formalin inactivated spores from a lethal Bacillus anthracis challenge under field conditions. BMC Veterinary Research, 2017, 13(1): 220 (doi: 10.1186/s12917-0171140-2).

116. Ndumnego O.C., Koehler S., Crafford J.E., Beyer W., van Heerden H. Immunogenicity of anthrax recombinant peptides and killed spores in goats and protective efficacy of immune sera in A/J mouse model. Scientific Reports, 2018, 8: 16937 (doi: 10.1038/s41598-018-35382-8).

117. Jauro S., Ndumnego O.C., Ellis C., Buys A., Beyer W., Heerden H.V. Immunogenicity and protective efficacy of a non-living anthrax vaccine versus a live spore vaccine with simultaneous penicillin-g treatment in cattle. Vaccine (Basel), 2020, 8(4): 595 (doi: 10.3390/vaccines8040595).

118. Gorantala J., Grover S., Rahi A., Chaudhary P., Rajwanshi R., Sarin N.B., Bhatnagar R. Generation of protective immune response against anthrax by oral immunization with protective antigen plantbased vaccine. Journal of Biotechnology, 2014, 176: 1-10 (doi: 10.1016/j.jbiotec.2014.01.033).

119. Koya V., Moayeri M., Leppla S.H., Daniell H. Plant-based vaccine: mice immunized with chloroplast-derived anthrax protective antigen survive anthrax lethal toxin challenge. Infection and Immunity, 2005, 73(12): 8266-8274 (doi: 10.1128/IAI.73.12.8266-8274.2005). 